\title{
HER2-Specific Pseudomonas Exotoxin A PE25 Based Fusions: Influence of Targeting Domain on Target Binding, Toxicity, and In Vivo Biodistribution
}

\author{
Haozhong Ding ${ }^{1,+}+\mathbb{D}$, Mohamed Altai ${ }^{2,+}$, Wen Yin ${ }^{1}{ }^{\mathbb{D}}$, Sarah Lindbo ${ }^{1}$, Hao Liu ${ }^{1}$, \\ Javad Garousi $^{3}(\mathbb{D})$, Tianqi Xu ${ }^{3}\left(\mathbb{D}\right.$, Anna Orlova ${ }^{4,5}$, Vladimir Tolmachev ${ }^{3,5}$, Sophia Hober ${ }^{1}$ \\ and Torbjörn Gräslund ${ }^{1, *(D)}$ \\ 1 Department of Protein Science, KTH Royal Institute of Technology, Roslagstullsbacken 21, \\ 11417 Stockholm, Sweden; haozhong@kth.se (H.D.); wenyin@kth.se (W.Y.); slindbo@kth.se (S.L.); \\ haoliu2@kth.se (H.L.); sophia@kth.se (S.H.) \\ 2 Department of Oncology and Pathology, Barngatan 4, Lund University, 22242 Lund, Sweden; \\ mohamed.altai@med.lu.se \\ 3 Department of Immunology, Genetics and Pathology, Dag Hammarskjölds väg 20, Uppsala University, \\ 75185 Uppsala, Sweden; javad.garousi@igp.uu.se (J.G.); tianqi.xu@igp.uu.se (T.X.); \\ vladimir.tolmachev@igp.uu.se (V.T.) \\ 4 Department of Medicinal Chemistry, Dag Hammarskjölds väg 14C; Uppsala University, \\ 75123 Uppsala, Sweden; anna.orlova@ilk.uu.se \\ 5 Research Centrum for Oncotheranostics, Research School of Chemistry and Applied Biomedical Sciences, \\ Tomsk Polytechnic University, 634050 Tomsk, Russia \\ * Correspondence: torbjorn@kth.se; Tel.: +46-(0)8-790-9627 \\ + These authors contributed equally to this work.
}

Received: 27 March 2020; Accepted: 22 April 2020; Published: 24 April 2020

Abstract: The human epidermal growth factor receptor 2 (HER2) is a clinically validated target for cancer therapy, and targeted therapies are often used in regimens for patients with a high HER2 expression level. Despite the success of current drugs, a number of patients succumb to their disease, which motivates development of novel drugs with other modes of action. We have previously shown that an albumin binding domain-derived affinity protein with specific affinity for HER2, $\mathrm{ADAPT}_{6}$, can be used to deliver the highly cytotoxic protein domain PE25, a derivative of Pseudomonas exotoxin A, to HER2 overexpressing malignant cells, leading to potent and specific cell killing. In this study we expanded the investigation for an optimal targeting domain and constructed two fusion toxins where a HER2-binding affibody molecule, $Z_{\text {HER2:2891, }}$ or the dual-HER2-binding hybrid $Z_{\text {HER2:2891-ADAPT }}$ were used for cancer cell targeting. We found that both targeting domains conferred strong binding to HER2; both to the purified extracellular domain and to the HER2 overexpressing cell line SKOV3. This resulted in fusion toxins with high cytotoxic potency toward cell lines with high expression levels of HER2, with $\mathrm{EC}_{50}$ values between 10 and $100 \mathrm{pM}$. For extension of the plasma half-life, an albumin binding domain was also included. Intravenous injection of the fusion toxins into mice showed a profound influence of the targeting domain on biodistribution. Compared to previous results, with $\mathrm{ADAPT}_{6}$ as targeting domain, $\mathrm{Z}_{\mathrm{HER} 2: 2891}$ gave rise to further extension of the plasma half-life and also shifted the clearance route of the fusion toxin from the liver to the kidneys. Collectively, the results show that the targeting domain has a major impact on uptake of PE25-based fusion toxins in different organs. The results also show that PE25-based fusion toxins with high affinity to HER2 do not necessarily increase the cytotoxicity beyond a certain point in affinity. In conclusion, $Z_{\text {HER2:2891 }}$ has the most favorable characteristics as targeting domain for PE25.

Keywords: pseudomonas exotoxin A; affibody molecule; half-life extension; cancer; HER2 


\section{Introduction}

Therapeutic approaches targeting particular pathways or molecular abnormalities on cancer cells have shown great progress during recent years and have led to impressive treatment responses in some cases. Overexpression of human epidermal growth factor receptor 2 (HER2) is a molecular abnormality that has attracted a lot of attention [1]. It is overexpressed in a significant number (approximately $25 \%$ ) of all breast cancers and to a lesser extent also in other cancer types [2]. HER2 is a single-pass plasma membrane anchored receptor that belongs to the epidermal growth factor receptor family. It can form homo- or hetero-dimers with other members of its family to trigger activation of e.g., the mitogen activated protein kinase (MAPK) and PI3K/Akt pathways [3]. This leads to a more aggressive phenotype which is characterized by increased proliferation, survival, and motility, and a poorer prognosis for the patient [4].

Several HER2-specific drugs have been approved by the US Food and Drug Administration (FDA) and the European Medicines Agency (EMA). These include the monoclonal antibodies (mAbs) trastuzumab [5] and pertuzumab [6], specifically targeting HER2. These also include the antibody drug conjugates trastuzumab emtansine, consisting of trastuzumab and a derivate of the cytotoxic tubulin polymerization inhibitor maytansine [7] and trastuzumab deruxtecan, an antibody-DNA topoisomerase 1 inhibitor conjugate [8]. Even though many patients respond well to these drugs, resistance develops in several cases [5], and a number of patients die of their HER2 overexpressing cancers.

This motivates development of HER2 specific drugs with other characteristics and modes of action. One possibility is to use a derivate of the well-studied Pseudomonas aeruginosa exotoxin A (ETA) where its natural targeting domain has been replaced with a targeting domain with specific affinity to the HER2 receptor. ETA is a highly cytotoxic enzyme that irreversibly modifies elongation factor 2 after entering the cell's cytosol, and thereby shuts-down all protein synthesis, which leads to cell death. The most extensively studied ETA-derivate is PE38, where domain 1, which is responsible for its natural cell interaction, has been deleted. PE38-based cancer drugs appear to be generally safe in humans [9] and recently the first PE38-based drug, moxetumomab pasudotox, targeting cluster of differentiation-22 (CD22), was approved by the US Food and Drug Administration for clinical use on adults with relapsed or refractory hairy cell leukemia [10]. Engineering of PE38 by removal of potential mouse and human, B- and T-cell epitopes [11-14] has led to several deimmunized variants. One of them is PE38X8, with the amino acid alterations R313A, Q332S, R432G, R467A, R490A, R513A, R513A, E548S, K590S, to remove B-cell epitopes [12]. Another variant is PE25 where domain II was replaced with a furin cleavage site followed by the amino acids GGS as well as the deimmunizing amino acid alterations R313A, Q332S, R432G, R467A, R490A, R513A, R513A, E548S, K590S [15,16]. Both PE38X8 and PE25 are highly potent cytotoxic protein domains, which can act on a variety of cell lines, however, their in vivo characteristics are relatively unexplored.

The most frequently used targeting domains to direct ETA-derived toxins to tumor cells are antibody fragments. For example, moxetumomab pasudotox utilizes a variable fragment (Fv) with a Mw of approximately $25 \mathrm{kDa}$, derived from immunoglobulin G, to target CD22 [17].

In recent years, other types of targeting domains for ETA-derived toxins that are built on alternative, non-Ig scaffolds, have started to emerge. One class of such targeting domains are the affibody molecules. They are small (58 amino acids, Mw $7 \mathrm{kDa}$ ), robust protein domains that usually fold into an anti-parallel three helix bundle structure. Affibody molecules binding specifically to several cancer relevant cell surface receptors have been generated, including epidermal growth factor receptor (EGFR) [18], HER2 [19], human epidermal growth factor receptor 3 (HER3) [20], insulin-like growth factor 1 receptor (IGF1R) [21], and carbonic anhydrase IX (CAIX) [22]. Affibody molecules targeting different receptors appear to be generally safe when injected into humans [23]. The affibody molecule, $\mathrm{Z}_{\mathrm{HER} 2: 2891}$, has strong affinity (equilibrium dissociation constant, $\mathrm{K}_{\mathrm{D}}, 66 \mathrm{pM}$ ) to HER2. It has previously been found to be able to specifically deliver PE38X8 to HER2 overexpressing cells [24]. Moreover, a ${ }^{68} \mathrm{Ga}$-labeled variant of $\mathrm{Z}_{\mathrm{HER} 2: 2891,}{ }^{68} \mathrm{Ga}-\mathrm{ABY}-025$, has shown excellent accumulation in 
metastases with HER2 expression in breast cancer patients, validating its ability for specific targeting of HER2 in a clinical context [25].

Another class of engineered scaffold proteins, developed as targeting domains, are the albumin binding domain-derived affinity proteins (ADAPTs). They consist of only 46 amino acids (Mw $5 \mathrm{kDa}$ ) and, like the affibody molecules, fold into an anti-parallel three helix bundle structure. ADAPTs with strong and specific affinity to different cancer relevant receptors have been developed, including HER2 and HER3 [26,27]. Studies with the HER2-binding radiolabeled ADAPT $_{6}$ demonstrated that this engineered scaffold protein is capable of specific accumulation in HER2-expressing human xenografts in mice $[28,29]$. Moreover, clinical data show that radiolabeled ADAPT 6 accumulates in HER2-expressing malignant breast tumors [30].

Fusion proteins consisting of affibody molecules or ADAPTs coupled to PE38X8 or PE25, result in constructs that will be smaller than the cut-off of the glomerular filtration in the kidneys, which is approximately $60 \mathrm{kDa}$, and will therefore likely be quickly cleared from circulation in vivo. $\mathrm{ADAPT}_{6}$-PE25, targeting HER2 overexpressing cells, was for example quickly cleared from circulation in mice; the concentration in blood was only $0.2 \pm 0.1 \% \mathrm{ID} / \mathrm{g}$ at $4 \mathrm{~h}$ after injection [31]. Addition of an albumin binding domain (ABD) to proteins smaller than the cut-off of the glomerular filtration has previously been found to extend their plasma half-life [32]. When injected, such constructs immediately associate with albumin and the size of the complex is thereby increased by the molecular weight of albumin $(67 \mathrm{kDa})$ to above the cut-off value. In addition, since albumin has an unusually long plasma half-life due to its interaction with the neonatal Fc receptor [33], fusion proteins including an ABD receive an extension of the plasma half-life from indirect interaction, via serum albumin, with the neonatal Fc receptor. The scaffold used for generation of ADAPTs is an albumin binding domain and the derivate $\mathrm{ABD}_{035}$ is an engineered version with femtomolar affinity $\left(\mathrm{K}_{\mathrm{D}}\right)$ for human serum albumin (HSA) [34].

Previously, we have found that $\mathrm{ADAPT}_{6}$ may be used for targeting of PE38X8 and PE25 to HER2 overexpressing cells [31]. However, biodistribution experiments in mice showed that the uptake varied considerably between different organs, a consequence of differences between PE38X8 and PE25. Significant differences were also found when comparing $\mathrm{Z}_{\mathrm{HER} 2: 2891}$ and $\mathrm{ADAPT}_{6}$ as targeting domains for PE38X8. It is obvious that different constituents of a complex fusion protein may influence each other's binding to their respective targets by e.g., imposing steric hindrance. Moreover, different constituents have different patterns of off-target interaction, which might enhance or attenuate uptake in normal tissues, and thus the biodistribution pattern of a fusion protein as well as its toxicity. This motivated us to extend our investigation of the properties of $Z_{\text {HER2:2891 }}$ as targeting domain of PE25 based fusion toxins.

In the present study, we created two affibody-PE25 fusion toxins. One utilizes $Z_{\text {HER2:2891 }}$ to target HER2 and the other utilizes a dual-HER2-binding domain consisting of $Z_{\text {HER2:2891 }}$ and ADAPT $_{6}$. The fusion toxins were thoroughly characterized concerning biochemical properties and in vitro toxicity on cells with different expression level of HER2. The biodistribution of both constructs was also investigated head-to-head in mice.

\section{Materials and Methods}

\subsection{General}

All chemicals and reagents were from Sigma-Aldrich (Saint Louis, MO, USA) or Merck (Kenilworth, NJ, USA) unless otherwise noted. DNA restriction enzymes and ligase were from New England Biolabs (Ipswich, MA, USA).

\subsection{Gene Construction}

pET26-ADAPT 6 -ABD-PE25 [31] was used as starting point for construction of expression vectors. Its expression cassette consists of an $\mathrm{N}$-terminal tag with the amino acid sequence HEHEHE followed 
by $\mathrm{ADAPT}_{6}$, an $\mathrm{ABD}$ and PE25. The vector was fitted with a NdeI and BamHI restriction sites surrounding $\mathrm{ADAPT}_{6}$. The expression vector for $\mathrm{Z}_{\mathrm{HER} 2: 2891}-\mathrm{ABD}-\mathrm{PE} 25$ was created by replacing $\mathrm{ADAPT}_{6}$ in $\mathrm{pET} 26-\mathrm{ADAPT}_{6}$-ABD-PE25 with $\mathrm{Z}_{\mathrm{HER2} 22891}$, using the NdeI and BamHI restriction sites. The expression vector for $Z_{\text {HER2:2891-ADAPT }}$-ABD-PE25 was created by inserting $Z_{\text {HER2:2891-ADAPT }}$, which was obtained by gene synthesis from Thermo Fisher Scientific (Waltham, MA, USA), using the NdeI and BamHI restriction sites. The $\mathrm{ABD}$ used was $\mathrm{ABD}_{035}$, a version engineered for high affinity to human serum albumin [34]. PE25 is a deimmunized and minimized version of PE38 with the following amino acid alterations: R427A, F443A, D463A, R467A, L477H, R490A, R494A, R505A, R538A, L552E, and deletion of the majority of domain II ( $\Delta 251-273$ and $\Delta 285-394)$ [12]. A furin cleavage site is at the $\mathrm{N}$-terminus of PE25 and is connected to domain III with a linker with the amino acid sequence GGS. All constructs were verified by DNA sequencing.

\subsection{Protein Expression and Purification}

Escherichia coli (BL21 Star (DE3)) (Merck Millipore, Billerica, Massachusetts, USA) was used as a host for protein expression. Overnight cultures of cells harboring the expression plasmids were prepared and diluted 1:100 in tryptic soy Broth (TSB) medium with yeast extract [31] and grown at $37^{\circ} \mathrm{C}$. When $\mathrm{OD}_{600}$ reached approximately 1.5 , protein expression was induced by addition of Isopropyl $\beta$-D-1-thiogalactopyranoside to a final concentration of $1 \mathrm{mM}$. The cells were grown a further $2.5 \mathrm{~h}$, after which they were harvested by centrifugation. The cell pellets were subsequently resuspended in TST-buffer ( $25 \mathrm{mM}$ Tris(hydroxymethyl) aminomethane, $1 \mathrm{mM}$ EDTA, $200 \mathrm{mM} \mathrm{NaCl}$, $0.05 \%$ Tween $20 \mathrm{pH} 8.0$ ) supplemented with Complete EDTA-free protease inhibitor cocktail (Roche Diagnostic, Basel, Switzerland) and then broken by sonication. The fusion toxins were purified on an HiTrap NHS sepharose column (GE Healthcare Bio-Sciences, Uppsala, Sweden) with immobilized HSA, as previously described [31]. The proteins were eluted with $0.5 \mathrm{M}$ acetic acid ( $\mathrm{pH}$ 2.6) followed by buffer exchange to phosphate buffered saline (PBS). The molecular masses of the eluted proteins were determined by liquid chromatography electrospray ionization mass spectrometry on a Bruker impact II instrument (Agilent Technologies, Santa Clara, CA, USA), as previously described [31].

\subsection{Biosensor Analysis}

Biacore 3000 and T200 instruments (GE Healthcare, Uppsala, Sweden) were used for biosensor analysis of interaction with serum albumins and HER2, respectively. HER2 (the extracellular domain, Sino Biological, Beijing, China) was immobilized, by amine coupling, on a CM5 sensor chip (GE Healthcare) with sodium acetate buffer ( $\mathrm{pH} 4.5$ ) as immobilization buffer. HSA (Novozymes, Bagsvaerd, Denmark) and mouse serum albumin (MSA) (Sigma-Aldrich) were immobilized on a second CM5-chip. The final immobilization level of HER2 was 320 RU. HSA and MSA were immobilized to a final level of 265 and $207 \mathrm{RU}$, respectively. Reference flow cells were created by activation and deactivation on both chips. As running buffer and for dilution of the analytes, HBS-EP $(10 \mathrm{mM} \mathrm{HEPES}, 150 \mathrm{mM} \mathrm{NaCl}$, $3 \mathrm{mM}$ EDTA, $0.05 \%$ Tween 20, pH 7.4) was used. All experiments were performed at $25^{\circ} \mathrm{C}$ with a flow rate of $50 \mu \mathrm{L} / \mathrm{min}$.

\subsection{Cell Culture}

SKOV3, SKBR-3, AU565, and A549 cell lines were obtained from the American Type Culture Collection (ATCC) and were grown in McCoy's 5a or Dulbecco's Modified Eagle's medium in a humidified incubator at $37{ }^{\circ} \mathrm{C}$ in $5 \% \mathrm{CO}_{2}$ atmosphere. The cells were grown for a maximum of 3 months after which the cell cultures were restarted from a frozen aliquot from the cell bank.

\subsection{Flow Cytometry Analysis}

To evaluate binding to HER2 on cells, SKOV3 (with high HER2 expression) was used. Samples of $1 \times 10^{5}$ cells were collected and incubated with different concentrations of the fusion toxins, diluted in $100 \mu \mathrm{L}$ PBSB-buffer (PBS with $1 \%$ BSA) for $2 \mathrm{~h}$ at $25^{\circ} \mathrm{C}$. Then, the cells were counterstained with 
Alexa Fluor 647-labeled HSA. Between each incubation step, the cells were washed once with PBSB. The fluorescence of the cells was measured in a Galios flow cytometer (Beckman Coulter, Stockholm, Sweden), where 10,000 events were recorded for each sample.

\subsection{Radiolabeling with ${ }^{99 m} \mathrm{Tc}$ and ${ }^{111}$ In}

Labeling of $\mathrm{Z}_{\mathrm{HER} 2: 2891}-\mathrm{ABD}-\mathrm{PE} 25$ and $\mathrm{Z}_{\mathrm{HER} 2: 2891}-\mathrm{ADAPT}_{6}$-ABD-PE25 with ${ }^{99 \mathrm{~m}} \mathrm{Tc}$ for measurement of their binding to living cells was performed according to methodology described earlier [35].

Briefly, a ${ }^{99} \mathrm{Mo} /{ }^{99 \mathrm{~m}} \mathrm{Tc}$ generator eluate containing ${ }^{99 \mathrm{~m}} \mathrm{Tc}_{-} \mathrm{TcO}_{4}{ }^{-}(500 \mu \mathrm{L}, 3-3.5 \mathrm{GBq})$ was added to a vial containing CRS kit (PSI, Villigen, Switzerland). The sealed vial was incubated at $100{ }^{\circ} \mathrm{C}$ for $30 \mathrm{~min}$. Thereafter, $15 \mu \mathrm{L}$ of solution containing ${ }^{99 \mathrm{~m}} \mathrm{Tc}(\mathrm{CO})_{3}$ was transferred to a vial containing $75 \mu \mathrm{g}$ of protein in $85 \mu \mathrm{L}$ PBS. After $60 \mathrm{~min}$ incubation at $42^{\circ} \mathrm{C}$, a 5000 -fold excess of histidine was added, and the mixture was incubated for $30 \mathrm{~min}$ at $42^{\circ} \mathrm{C}$. Radiolabeled proteins were purified by passage through a NAP-5 size-exclusion column (GE Healthcare). The radiochemical purities of the labelled proteins were $98.8-99 \%$.

Labeling of $Z_{\text {HER2:2891-ABD-PE25 }}$ and $Z_{\text {HER2:2891-ADAPT }}$-ABD-PE25 with ${ }^{111}$ In for biodistribution measurements was performed as previously described for $\mathrm{ADAPT}_{6}$-ABD-PE25 [31]. Briefly, a CHX-A"-DTPA chelator was conjugated to the fusion toxins by incubation of 1.1-fold molar excess of the chelator with protein in $0.07 \mathrm{M}$ sodium borate, $\mathrm{pH} 9.3$, at room temperature overnight. Thereafter, an excess of unreacted chelator was removed, and buffer was changed by passing the mixture through a NAP-5 column, pre-equilibrated and eluted with $0.2 \mathrm{M}$ ammonium acetate ( $\mathrm{pH}$ 5.5). For labeling, $200 \mu \mathrm{g}$ conjugate was mixed with ${ }^{111} \mathrm{InCl}(8-10 \mathrm{MBq}$ in $0.05 \mathrm{M} \mathrm{HCl})$, and the mixture was incubated for $60 \mathrm{~min}$ at room termperature. The radiolabeled proteins were purified using NAP-5 size-exclusion columns. The radiochemical purities of conjugates were over $95 \%$.

\subsection{Binding Studies Using a Ligandtracer Instrument}

Affinity measurements against HER2 expressing cells were performed in real time using a Ligandtracer instrument (Ridgeview Diagnostics, Uppsala, Sweden) [36]. For this, SKOV3 cells $\left(2 \times 10^{6}\right)$ were seeded in one area of a $10 \mathrm{~cm}$ petri dish one day before the experiment. After adding $3 \mathrm{~mL}$ of complete media, the dish was placed on the rotating table of the instrument and measured for $30 \mathrm{~min}$ as baseline. Two concentrations of each ${ }^{99 \mathrm{~m}} \mathrm{Tc}$ labeled fusion toxin (6 and $\left.18 \mathrm{nM}\right)$ were subsequently added to the cells and each concentration was measured for $90 \mathrm{~min}$. For the dissociation phase, the medium was replaced with $3 \mathrm{~mL}$ of fresh medium and the measurement was continued overnight. The experiment was performed in duplicate at room temperature.

To evaluate the kinetics and stoichiometry of the interaction, an Interaction Map (Ridgeview Diagnostics) analysis was performed for each curve and the results were plotted by Tracedrawer software (Ridgeview Diagnostics).

\subsection{Cell Binding Specificity Test}

Approximately $1 \times 10^{6} \mathrm{SKOV} 3$ cells/well were seeded in a 6-well plate. On the following morning cells were washed once with $1 \mathrm{~mL}$ complete medium. Then, $1000 \mathrm{nM}$ of non-labeled compound in $500 \mu \mathrm{L}$ medium, or same volume of fresh medium, was added to each well $(n=3) 15-30 \mathrm{~min}$ prior to addition of radiolabeled compound. Next, $4 \mathrm{nM}$ of radiolabeled fusion toxin was added to each well to a final concentration of $2 \mathrm{nM}$ and the 6-well plate was incubated at $37^{\circ} \mathrm{C}$ for $1 \mathrm{~h}$. After incubation, the wells were washed twice with PBS and the cells were detached by addition of a Trypsin-EDTA solution. The radioactivity of the cells was analyzed in an automated gamma-counter.

\subsection{In Vitro Cytotoxicity Analysis}

Cell viability was assessed by measurement of intracellular dehydrogenases activity using the Cell counting kit-8 assay (Sigma-Aldrich). To determine the cytotoxicity of each fusion toxin for each 
cell line, approximately 5000 cells/well were seeded in a 96-well plate and were allowed to attach for $4 \mathrm{~h}$. The medium was then replaced with fresh medium containing the indicated concentrations of the fusion toxins, followed by incubation for $72 \mathrm{~h}$ at $37^{\circ} \mathrm{C}$. The cells were washed with PBS, and viability was measured according to the supplier's protocol, with determination of $\mathrm{A}_{450}$ in each well. The obtained absorbance values were plotted and analyzed by Prism 8 (GraphPad Software, La Jolla, CA, USA).

\subsection{Biodistribution Experiments}

The animal experiments were planned and performed according to Sweden's national legislation on laboratory animals' protection. The animal studies were approved (project identifier: $86 / 15$ ) by the local ethics committee for animal research in Uppsala, Sweden, on 18 June 2016.

Biodistribution of ${ }^{111}$ In-labeled $Z_{\text {HER2:2891-ABD-PE25 and } Z_{\text {HER2:2891-ADAPT }}-A B D-P E 25}$ was measured in exactly the same way as biodistribution of ${ }^{111}{ }^{1 n}-\mathrm{ADAPT}_{6}-\mathrm{ABD}-\mathrm{PE} 25$ previously [31], using female NMRI mice (Taconic Biosciences, Ejby, Denmark). The mice were 10 weeks old upon arrival, and their weight was $26 \pm 2 \mathrm{~g}$ at the time of the experiment. A group of four mice was used per data point. Euthanasia was performed using i.p. injection of a mixture of Ketalar (200 mg/kg body weight) and Rompun (20 mg/kg body weight).

${ }^{111}$ In-Z $Z_{\text {HER2:2891-ABD-PE25 and }}{ }^{111}{ }^{I n}-Z_{\text {HER2:2891-ADAPT }}-$-ABD-PE25 $(1 \mu \mathrm{g} / 20 \mathrm{kBq}$ in $100 \mu \mathrm{L}$ PBS containing $2 \%$ BSA per animal) were injected in the tail veins of the mice. At 4 and $24 \mathrm{~h}$ after injection, the animals were injected with a lethal dose of anesthetic and exsanguinated using a heparinized syringe. Organs and tissue samples were collected, weighed, and their radioactivity was measured using an automated gamma-spectrometer.

\section{Results}

\subsection{Construct Design, Protein Expression, and Purification}

The HER2 specific fusion toxins are schematically outlined in Figure 1a. The targeting part consists of the HER2 specific affibody molecule $Z_{\text {HER2:2891 }}$ or the dual HER2 targeting hybrid, $\mathrm{Z}_{\mathrm{HER} 2: 2891}-\mathrm{ADAPT}_{6}$. An albumin binding domain (ABD) was included in both constructs for in vivo half-life extension. In both cases the domain PE25, a deimmunized and truncated version of Pseudomonas aeruginosa exotoxin $\mathrm{A}$, was used for its cytotoxic capacity. All domains were connected with linkers with the amino acid sequence $\left(\mathrm{S}_{4} \mathrm{G}\right)_{4}$ and both fusion toxins were fitted with an N-terminal tag with the amino acid sequence HEHEHE, suitable for radionuclide chelation. The fusion toxins were expressed in the cytoplasm of Escherichia coli. The strong HSA affinity presented by ABD was capitalized upon, and the fusion toxins were purified by a single affinity chromatographic step, utilizing a column with immobilized HSA. Eluted material was pooled and analyzed by sodium dodecyl sulfate-polyacrylamide gel electrophoresis (SDS-PAGE) showing pure and homogenous proteins (Figure $1 \mathrm{~b}$ ). The molecular weights of the proteins were confirmed by mass spectrometry (Figure S1) to be 41.8 and $48.9 \mathrm{kDa}$ for $\mathrm{Z}_{\mathrm{HER} 2: 2891}-\mathrm{ABD}-\mathrm{PE} 25$ and $\mathrm{Z}_{\mathrm{HER} 2: 2891}-\mathrm{ADAPT}_{6}-\mathrm{ABD}_{\mathrm{BE}}$-P5, respectively. The proteins were further analyzed by passage through a size-exclusion chromatography column and were eluted as single symmetrical peaks with retention times expected of monomers, showing that no di- or multimers were formed (Figure 1c). 


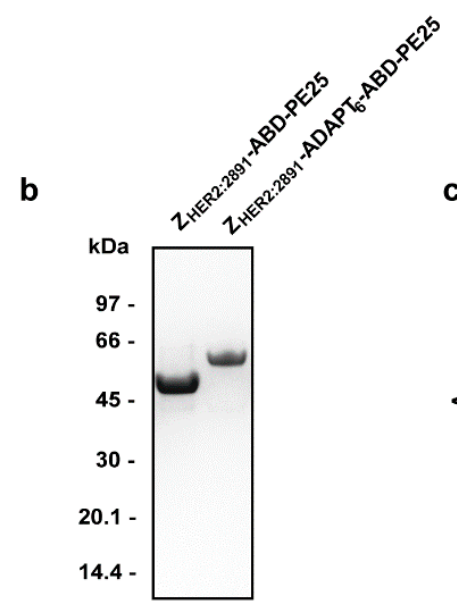

C

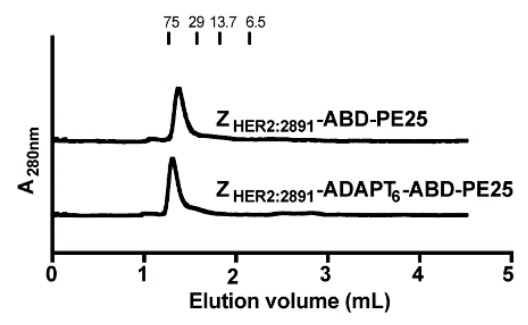

Figure 1. Schematic description and initial biochemical characterization of the fusion toxins. (a) A schematic description of the fusion toxins analyzed in the current study along with their theoretical molecular weights. The individual domains of the fusion toxins were connected with linkers with the amino acid sequence $\left(\mathrm{S}_{4} \mathrm{G}\right)_{4}$. After purification by affinity chromatography with immobilized human serum albumin (HSA), the fusion toxins were analyzed by sodium dodecyl sulfate-polyacrylamide gel electrophoresis (SDS-PAGE) under reducing conditions (b). The numbers to the left indicate molecular weights of reference proteins. The fusion toxins were also analyzed by analytical size exclusion chromatography and the recorded chromatograms are shown in (c). The numbers above the chromatograms correspond to elution volumes of reference proteins.

\subsection{Interaction of the Fusion Toxins with HER2}

The interaction of the fusion toxins with HER2 was investigated by real time biosensor analyses on a Biacore instrument. HER2 was immobilized on the chip surface and dilution series of the fusion toxins were sequentially injected (Figure 2a,b). A concentration dependent response was recorded after blank subtraction, showing that both fusion toxins could interact with HER2. For $Z_{\text {HER2:2891-ABD-PE25, }}$ the kinetic constants were derived assuming a 1:1 interaction and $K_{D}$ was determined to $1.9 \mathrm{nM}$. Since $\mathrm{Z}_{\mathrm{HER} 2: 2891}-\mathrm{ADAPT}_{6}-\mathrm{ABD}-\mathrm{PE} 25$ contains two HER2-interacting domains, the kinetic constants for interaction with HER2 cannot be derived assuming a 1:1 interaction model. In this case the kinetic constants were derived assuming a bivalent analyte binding model. Visual comparison of the dissociation phase in Figure $2 a, b$ shows that the off-rate is slower for $Z_{\text {HER2:2891-ADAPT }}$-ABD-PE25

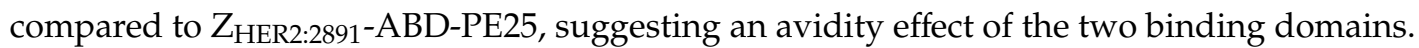

Further, the interaction of the fusion toxins with cells were investigated by flow cytometry. SKOV3 cells with high HER2 expression were incubated with the fusion toxins followed by detection with fluorescently labeled HSA that should bind to the ABD-part. A concentration dependent response was obtained showing that the fusion proteins could indeed interact with SKOV3 cells (Figure 2c,d). 


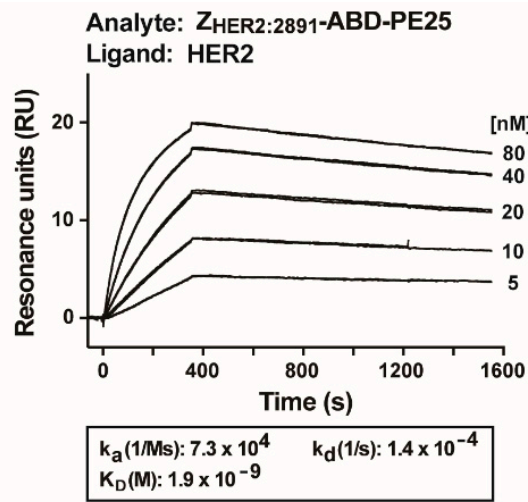

C

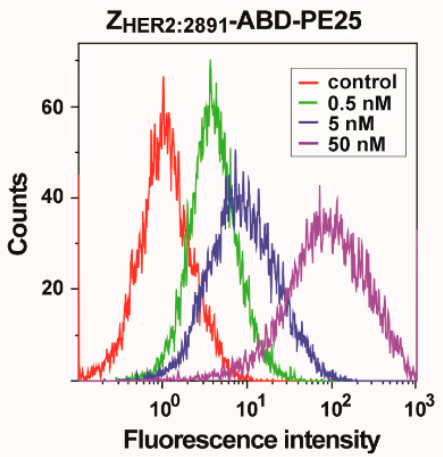

e

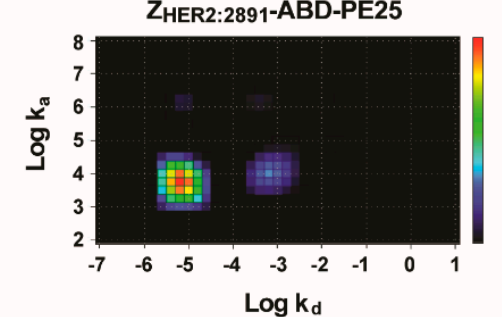

b

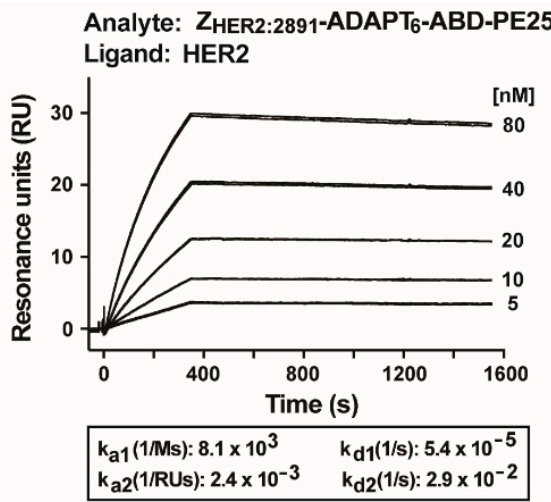

d

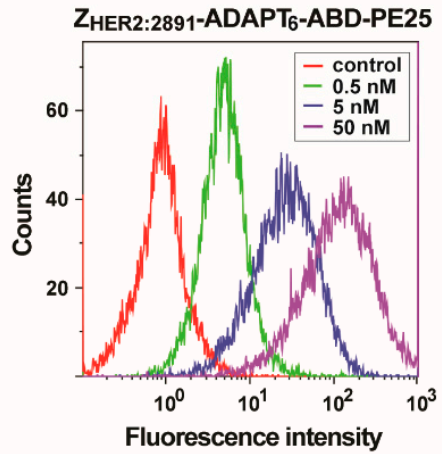

f

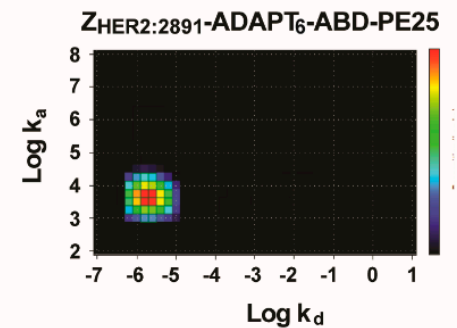

Figure 2. Analysis of the interaction with HER2. (a,b) Sensorgrams after analyses using a Biacore real-time biosensor of the interaction of the fusion toxins with HER2. Dilution series of the fusion toxins were injected sequentially over a surface with immobilized HER2. Each concentration was injected twice, and each panel is an overlay of both repeats of all concentrations. The injected concentrations are indicated to the right of each panel. SKOV3 cells were stained with different concentrations of the fusion toxins, followed by staining with fluorescently labeled human serum albumin (HSA) and were analyzed by flow cytometry $(\mathbf{c}, \mathbf{d})$. The concentration of the fusion toxins used for staining is indicated in the legend. Each panel is an overlay of the plots obtained for all concentrations for each fusion toxin. The controls are non-stained cells. Further, the fusion toxins were radiolabeled with ${ }^{99 \mathrm{~m}} \mathrm{Tc}$ and incubated with SKOV3 cells and cell bound radioactivity was recorded as a function of time in a Ligandtracer instrument. The obtained curves were analyzed by Tracedrawer software and the resulting Interaction Maps are presented in (e,f).

To determine the $\mathrm{K}_{\mathrm{D}}$ of the interactions between the radiolabeled fusion toxins and SKOV3 cells, the HEHEHE-tag of the fusion toxins were radiolabeled with ${ }^{99 \mathrm{~m}} \mathrm{Tc}$ and added to a rotating dish with SKOV3 cells in a Ligandtracer instrument. The results were analyzed by Interaction Map software to determine the $\mathrm{K}_{\mathrm{D}}$ and stoichiometry of the interactions (Figure 2e,f). For both fusion toxins, the interaction was dominated by a primary event with a minor secondary event, showing that in both cases the stoichiometry of the interaction is primarily a 1:1 interaction. Surprisingly, the secondary event is more pronounced for the $Z_{\mathrm{HER} 2: 2891-A B D-P E 25 / S K O V 3}$ interaction, that theoretically is a 1:1 interaction, than for the $\mathrm{Z}_{\mathrm{HER} 2: 2891}-\mathrm{ADAPT}_{6}-\mathrm{ABD}-\mathrm{PE} 25 / \mathrm{SKOV} 3$ interaction, that theoretically is a 2:1 
interaction. The secondary event for the $\mathrm{Z}_{\mathrm{HER2} 22891}-\mathrm{ADAPT}_{6}-\mathrm{ABD}-\mathrm{PE} 25 / \mathrm{SKOV} 3$ interaction might be difficult to see in Figure $2 \mathrm{f}$, and accounts for $<1 \%$ of the interaction. The primary event for the interaction between $\mathrm{Z}_{\mathrm{HER} 22891}-\mathrm{ABD}-\mathrm{PE} 25$ and SKOV3 is centered around a $\mathrm{K}_{\mathrm{D}}$ of $1.8 \mathrm{nM}$. The primary event for the $Z_{\text {HER2:2891-ADAPT }}$-ABD-PE25/SKOV3 interaction is centered around a $K_{D}$ of $0.47 \mathrm{nM}$. The results showed that the interaction between both fusion toxins and SKOV3 is similar. It also suggests that one of the HER2 binding domains of $Z_{\text {HER2:2891-ADAPT }}$-ABD-PE25 is contributing almost exclusively to the interaction with the cells.

To ascertain that the radiolabeled fusion toxins did not stick non-specifically to the SKOV3 cells, a binding specificity experiments was performed (Figure S2). In that experiment, cells were incubated with a radiolabeled fusion toxin with or without pre-incubation with an excess of non-labeled fusion toxin. The results showed that for both fusion toxins, the radioactive signal could to a large extent be blocked by addition of an excess of cold fusion toxin, suggesting that the interaction of the radiolabeled fusion toxin with the cells was through the HER2 receptor.

\subsection{Analysis of Affinity to Serum Albumins}

The affinities of the fusion toxins to HSA and mouse serum albumin (MSA) were determined by real-time biosensor analyses on a Biacore instrument. To determine the kinetic constants and equilibrium dissociation constant $\left(K_{D}\right)$ of the interactions, dilution series of $Z_{\text {HER2:2891-ABD-PE25 }}$ and $Z_{\text {HER2:2891-ADAPT }}$-ABD-PE25 were injected over surfaces with immobilized HSA or MSA (Figure 3). The on-rate for $Z_{\text {HER2:2891-ADAPT }}$-ABD-PE25 was slower than for $Z_{\text {HER2:2891-ABD-PE25 }}$ on both the HSA and MSA surfaces. The off-rate of both fusion toxins on both surfaces were similar. This resulted in a slightly stronger affinity of $Z_{\text {HER2:2891-ABD-PE25 compared to }}$ $Z_{\text {HER2:2891-ADAPT }}$-ABD-PE25 on both the HSA and MSA surfaces. The $K_{D}$ was 1.1 and $3.5 \mathrm{nM}$ for the interaction between $Z_{\mathrm{HER} 2: 2891}-\mathrm{ABD}-\mathrm{PE} 25$ or $\mathrm{Z}_{\mathrm{HER2:2891}}-\mathrm{ADAPT}_{6}-\mathrm{ABD}-\mathrm{PE} 25$ and the HSA surface, respectively. The interaction with the MSA surface was weaker, 2.3 and $9.8 \mathrm{nM}$, respectively,

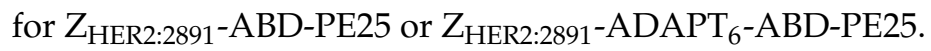


a

Analyte: Z ZER2:2891-ABD-PE25 Ligand: HSA

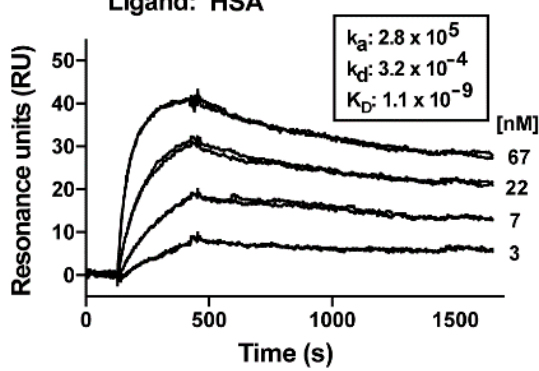

C Analyte: Z Z HER2:2891-ABD-PE25 Ligand: MSA

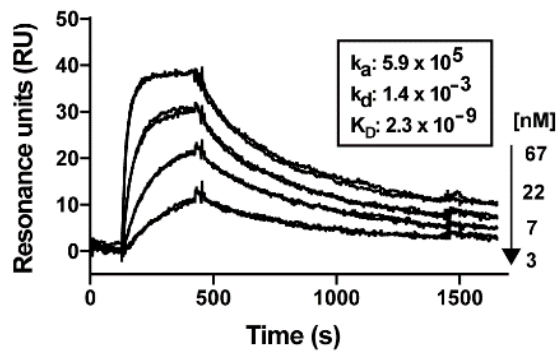

b Analyte: $\mathrm{Z}_{\mathrm{HER} \text { 2:2891-ADAPT }}$-ABD-PE25 Ligand: HSA

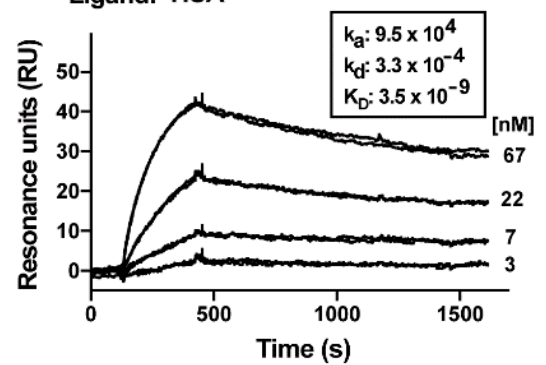

d Analyte: $Z_{\text {HER2:2891-ADAPT }}$-ABD-PE25 Ligand: MSA

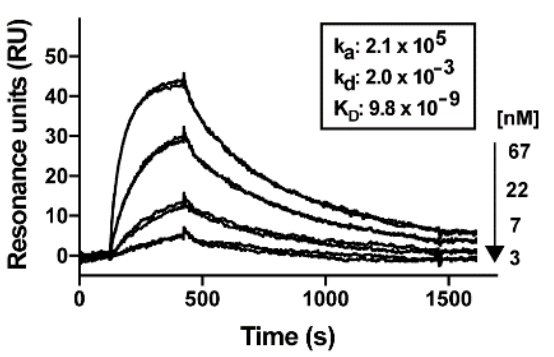

Figure 3. Analysis of the interaction between the fusion toxins and HSA and mouse serum albumin (MSA). The analyses were carried out a Biacore real-time biosensor instrument. A dilution series

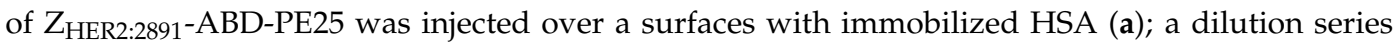
of $Z_{\text {HER2:2891-ADAPT }}$-ABD-PE25 was injected over a surface with immobilized HSA (b); a dilution

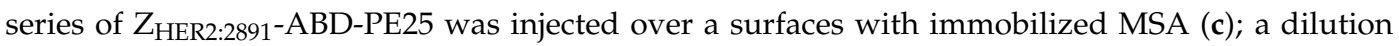
series of $Z_{\text {HER2:2891-ADAPT }}$-ABD-PE25 was injected over a surface with immobilized MSA (d). The concentrations are indicated to the right of each panel. Each concentration was injected twice and each panel is an overlay of the sensorgrams recorded for both repeats of each concentration for the whole dilution series.

\subsection{Cytotoxicity Analysis}

The cytotoxicity was determined by incubating dilution series of the fusion toxins with different cell lines (Figure 4). For high HER2 expressing cells: AU565 (breast carcinoma), SKBR-3 (breast carcinoma), and SKOV3 (ovarian carcinoma) the $\mathrm{EC}_{50}$ was between $10^{-10}$ and $10^{-11} \mathrm{M}$. This shows that the toxins are extremely potent on cells with high HER2 expression derived from epithelial tissues of different origin. Both fusion toxins were considerably less toxic to A549 (lung carcinoma), derived from epithelial tissue and with medium HER2 expression. 
a

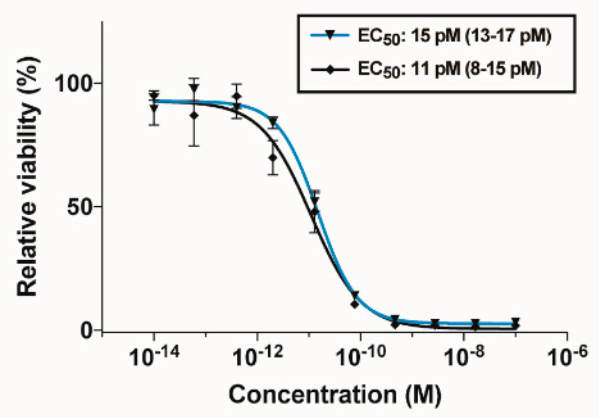

C

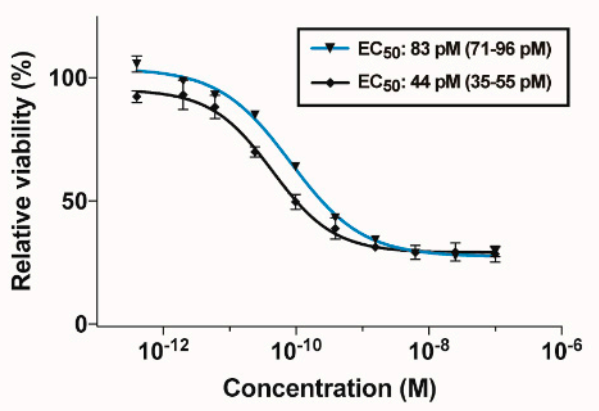

b

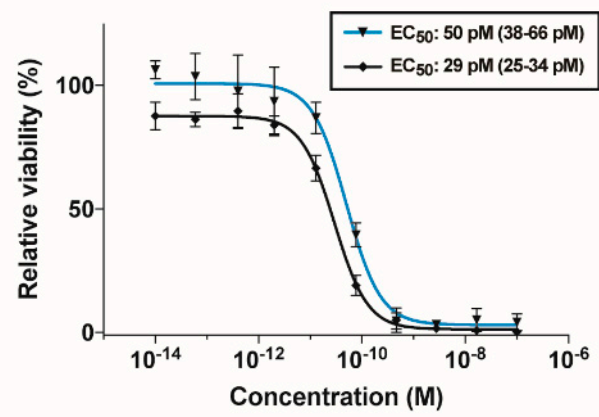

d

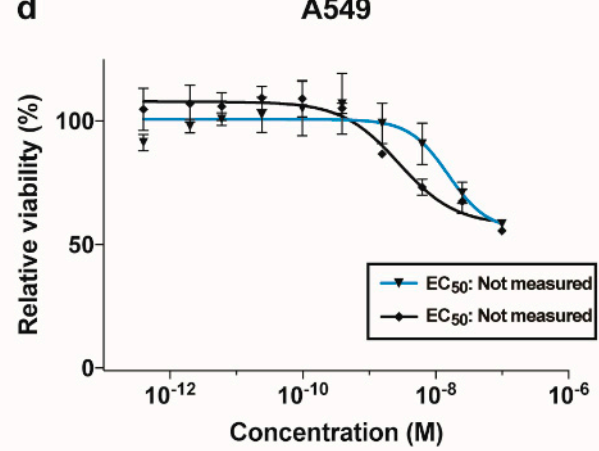

\section{$\rightarrow Z_{\text {HER2:2891-ABD-PE25 }}$ \\ $\rightarrow Z_{\text {HER2:2891-ADAPT }}$-ABD-PE25}

Figure 4. Determination of cytotoxic potency of fusion toxins. SKBR-3 (a), AU565 (b), SKOV3 (c) and A549 (d) cells were incubated with different concentrations of the fusion toxins and the viability of the cells was measured as a function of protein concentration. The viability of cells incubated without toxin (control cells) was set to $100 \%$. The measured viability was plotted as percent viability compared to control cells on the y-axis, as a function of the concentration of fusion toxin on the x-axis. Each data-point corresponds to the average viability of four independent experiments. The error bars correspond to $1 \mathrm{SD}$.

\subsection{Biodistribution}

The two fusion toxins were radiolabeled with ${ }^{111} \mathrm{In}$ and injected into mice and data concerning biodistribution of the fusion toxins were collected and are presented in Table 1. For comparison, historical data concerning the biodistribution of $\mathrm{ADAPT}_{6}-\mathrm{ABD}-\mathrm{PE} 25$ are included in the table [31]. Measurements performed $4 \mathrm{~h}$ after injection showed that blood retention was significantly higher

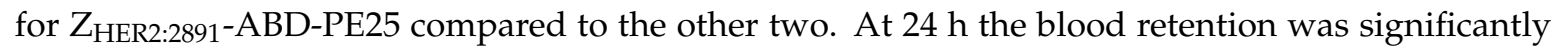

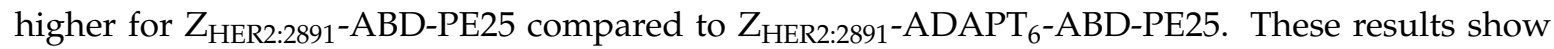

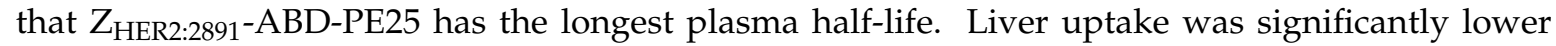
for $\mathrm{Z}_{\mathrm{HER2} 22891}-\mathrm{ABD}-\mathrm{PE} 25$ compared to $\mathrm{ADAPT}_{6}$-ABD-PE25. Conversely, kidney uptake at $4 \mathrm{~h}$ was lower for $\mathrm{ADAPT}_{6}-\mathrm{ABD}-\mathrm{PE25}$ compared to $\mathrm{Z}_{\mathrm{HER} 2: 2891}-\mathrm{ABD}-\mathrm{PE} 25$. Uptake in liver and kidneys of $Z_{\text {HER2:2891-ADAPT }}$-ABD-PE25, containing the dual-targeting domain was between the values

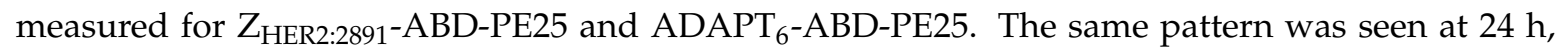
except that $Z_{\text {HER2:2891- }}-\mathrm{ADAPT}_{6}-\mathrm{ABD}-\mathrm{PE} 25$ had a higher uptake in liver compared to the other two. Collectively these results suggest that $Z_{\text {HER2:2891 }}$ promotes a clearance route through the kidneys and that $\mathrm{ADAPT}_{6}$ promotes a clearance route through the liver for PE25-based fusion toxins. 
Table 1. Comparative biodistribution of the ${ }^{111}$ In-labeled fusion toxins in mice 4 and $24 \mathrm{~h}$ following intravenous injection ${ }^{\mathrm{a}}$.

\begin{tabular}{|c|c|c|c|}
\hline & $\mathrm{Z}_{\text {HER2:2891-ABD-PE25 }}$ & $\mathrm{ADAPT}_{6}-\mathrm{ABD}-\mathrm{PE} 25^{\mathrm{e}}$ & $\mathrm{Z}_{\text {HER2:2891-ADAPT }}$-ABD-PE25 \\
\hline & \multicolumn{3}{|c|}{ At $4 \mathrm{~h}$ post-injection } \\
\hline Blood & $9.2 \pm 1.0^{\mathrm{c}, \mathrm{d}}$ & $3.2 \pm 0.1$ & $4.6 \pm 0.9$ \\
\hline Heart & $3.0 \pm 0.5^{c, d}$ & $1.1 \pm 0.2$ & $1.7 \pm 0.2$ \\
\hline Lung & $4.0 \pm 0.5^{\mathrm{c}, \mathrm{d}}$ & $1.3 \pm 0.1^{\mathrm{d}}$ & $2.2 \pm 0.5$ \\
\hline Salivary gland & $1.6 \pm 0.4^{\mathrm{c}, \mathrm{d}}$ & $0.7 \pm 0.2$ & $0.8 \pm 0.3$ \\
\hline Liver & $13.9 \pm 2.2^{c}$ & $42.4 \pm 6.8^{d}$ & $23.1 \pm 3.8$ \\
\hline Spleen & $6.2 \pm 2.0^{c}$ & $18.9 \pm 4.2^{\mathrm{d}}$ & $7.8 \pm 2.0$ \\
\hline Pancreas & $0.9 \pm 0.1$ & $0.4 \pm 0.1$ & $1.0 \pm 0.5$ \\
\hline Stomach & $1.0 \pm 0.1^{\mathrm{c}}$ & $0.5 \pm 0.2$ & $0.7 \pm 0.1$ \\
\hline Kidney & $40.1 \pm 4.8^{\mathrm{c}, \mathrm{d}}$ & $12.5 \pm 0.6^{\mathrm{d}}$ & $69.7 \pm 8.0$ \\
\hline Colon & $1.3 \pm 0.1^{\mathrm{c}}$ & $0.6 \pm 0.3$ & $1.0 \pm 0.3$ \\
\hline Skin & $1.5 \pm 0.5^{\mathrm{c}}$ & $0.6 \pm 0.1$ & $0.9 \pm 0.2$ \\
\hline Muscle & $0.7 \pm 0.1^{\mathrm{c}, \mathrm{d}}$ & $0.3 \pm 0.1$ & $0.4 \pm 0.1$ \\
\hline Bone & $1.4 \pm 0.1^{\mathrm{d}}$ & $1.1 \pm 0.3$ & $0.9 \pm 0.2$ \\
\hline GI tract ${ }^{b}$ & $3.5 \pm 0.5$ & $6.9 \pm 4.4$ & $3.3 \pm 1.1$ \\
\hline \multirow[t]{2}{*}{ Carcass $^{b}$} & $17.8 \pm 2.1^{\mathrm{c}, \mathrm{d}}$ & $3.5 \pm 2.8^{d}$ & $13.0 \pm 0.8$ \\
\hline & \multicolumn{3}{|c|}{ At $24 \mathrm{~h}$ post-injection } \\
\hline Blood & $2.6 \pm 0.5^{\mathrm{d}}$ & $2.0 \pm 0.1$ & $1.8 \pm 0.3$ \\
\hline Heart & $1.6 \pm 0.3$ & $1.8 \pm 0.2^{\mathrm{d}}$ & $1.2 \pm 0.1$ \\
\hline Lung & $1.8 \pm 0.3^{\mathrm{d}}$ & $1.7 \pm 0.2^{\mathrm{d}}$ & $1.2 \pm 0.1$ \\
\hline Sal gland & $1.2 \pm 0.3^{\mathrm{d}}$ & $1.2 \pm 0.1^{\mathrm{d}}$ & $0.8 \pm 0.1$ \\
\hline Liver & $8.7 \pm 0.9^{\mathrm{c}, \mathrm{d}}$ & $21.9 \pm 2.0$ & $16.2 \pm 1.7$ \\
\hline Spleen & $5.5 \pm 1.1^{c}$ & $8.5 \pm 1.7^{\mathrm{d}}$ & $5.3 \pm 1.3$ \\
\hline Pancreas & $0.6 \pm 0.1$ & $0.6 \pm 0.1$ & $0.5 \pm 0.1$ \\
\hline Stomach & $0.8 \pm 0.1$ & $0.7 \pm 0.1$ & $0.6 \pm 0.1$ \\
\hline Kidney & $33.4 \pm 4.4^{\mathrm{c}, \mathrm{d}}$ & $9.3 \pm 1.3^{\mathrm{d}}$ & $47.1 \pm 5.2$ \\
\hline Colon & $0.5 \pm 0.1^{c}$ & $0.9 \pm 0.1^{\mathrm{d}}$ & $0.5 \pm 0.1$ \\
\hline Skin & $2.0 \pm 0.4^{\mathrm{c}, \mathrm{d}}$ & $1.2 \pm 0.1$ & $1.3 \pm 0.1$ \\
\hline Muscle & $0.5 \pm 0.1$ & $0.5 \pm 0.1$ & $0.4 \pm 0.0$ \\
\hline Bone & $1.6 \pm 0.5$ & $1.8 \pm 0.3$ & $0.9 \pm 0.2$ \\
\hline GI tract ${ }^{b}$ & $1.5 \pm 0.1^{\mathrm{c}}$ & $2.7 \pm 0.7^{d}$ & $1.0 \pm 0.1$ \\
\hline Carcass ${ }^{b}$ & $16.4 \pm 1.5^{\mathrm{c}, \mathrm{d}}$ & $13.3 \pm 1.4$ & $11.8 \pm 1.1$ \\
\hline
\end{tabular}

a The measured radioactivity of different organs is expressed as $\% \mathrm{ID} / \mathrm{g}$ and presented as an average value from four animals $\pm 1 \mathrm{SD} .{ }^{\mathrm{b}}$ Data for gastrointestinal (GI) tract with content and carcass are presented as \%ID per whole sample. Data were assessed by one-way ANOVA with Bonferroni's post hoc multiple comparisons test in order to determine significant differences between groups $(p<0.05)$ at the same time point. No statistical analysis of values obtained for the same construct in the same organ at the two time-points was performed. ${ }^{c} p<0.05$ vs. $\mathrm{ADAPT}_{6}-\mathrm{ABD}-\mathrm{PE} 25 .{ }^{\mathrm{d}} p<0.05$ vs. $\mathrm{Z}_{\mathrm{HER} 2: 2891}-\mathrm{ADAPT}_{6}-\mathrm{ABD}-\mathrm{PE} 25 .{ }^{\mathrm{e}}$ Historical data [31].

Uptake in the spleen was also significantly lower for both fusion toxins containing $Z_{\mathrm{HER} 2: 2891}$ compared to $\mathrm{ADAPT}_{6}-\mathrm{ABD}-\mathrm{PE} 25$. This suggests that $\mathrm{ADAPT}_{6}$ promotes uptake in spleen, which 
has also been seen earlier [28]. The promoted uptake in spleen by $\mathrm{ADAPT}_{6}$ can be counteracted by $\mathrm{Z}_{\mathrm{HER} 2: 2891 \text {. }}$

\section{Discussion}

In the present study, we investigated different targeting domains for delivery of PE25-based fusion toxins to HER2 overexpressing cells. We designed two toxin fusions, $Z_{\text {HER2:2891-ABD-PE25 } 5 \text { and }}$ $\mathrm{Z}_{\mathrm{HER} 2: 2891}-\mathrm{ADAPT}_{6}-\mathrm{ABD}-\mathrm{PE} 25$, and investigated their properties in vitro and in vivo.

Both fusion toxins could be produced in a soluble form in Escherichia coli and efficiently purified to homogeneity by a single affinity chromatography step. This is an advantage from a manufacturing point of view compared to immunotoxins utilizing e.g., an immunoglobulin-derived Fv fragment. Although such immunotoxins can also be expressed in Escherichia coli, they typically form inclusion bodies [37] that require solubilization and refolding, which leads to a much more cumbersome purification process.

Interaction analyses in vitro were performed by several different methods. Determination of the kinetic constants by real-time biosensor interaction in a Biacore instrument for $Z_{\text {HER2:2891-ABD-PE25 }}$ for HER2 is straight-forward as it should follow a Langmuir 1:1 interaction. To analyze the interaction between $\mathrm{Z}_{\mathrm{HER} 2: 2891}-\mathrm{ADAPT}_{6}$-ABD-PE25 and HER2 is more difficult, since it contains two different targeting domains. A possibility is to utilize the bivalent analyte binding model in the Biacore software package, as we have done in this study. However, it assumes that the two HER2-binding parts of $\mathrm{Z}_{\mathrm{HER} 2: 2891}-\mathrm{ADAPT}_{6}-\mathrm{ABD}-\mathrm{PE} 25$ are interacting identically with HER2, as would e.g., the two antigen binding arms of an antibody. Since the kinetic constants for the interaction between $\mathrm{ADAPT}_{6}$-ABD-PE25 and HER2 [31] is different from the kinetic constants derived for the interaction

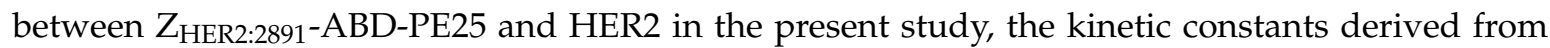
the bivalent analyte binding model for $\mathrm{Z}_{\mathrm{HER2} 22891}-\mathrm{ADAPT}_{6}-\mathrm{ABD}-\mathrm{PE} 25$ can only be regarded as an approximation. A possibility would be to reverse the set-up and immobilize the fusion toxins on the chip-surface followed by injection of soluble HER2. However, that experimental set-up is inferior to the current one in terms of modeling binding to cells, since HER2's natural context is on the cell surface. Binding to cells was instead investigated by incubating SKOV3 cells with different concentration of the fusion toxins, followed by staining with fluorescently labeled HSA and analysis by flow cytometry, showing an increase in fluorescence signal with increasing concentration. An important observation from this experiment is that both fusion toxins could bind to HSA and HER2 simultaneously. Due to the ubiquitously present HSA in the blood stream, simultaneous binding to HER2 and HSA will likely be required for efficient tumor targeting in vivo. The kinetic constants and the affinity between the fusion toxins and SKOV3 cells were determined using a Ligandtracer instrument followed by analysis by Tracedrawer software. Interestingly, the primary event in the interaction between $Z_{\text {HER2:2891-ABD-PE25 }}$ and HER2 was $1.8 \mathrm{nM}$, which was close to the $\mathrm{K}_{\mathrm{D}}$-value for the same interaction determined in the Biacore instrument $(1.9 \mathrm{nM})$. This shows that the set-up in the Biacore mimics the interaction with the cells relatively well in this case, despite that HER2 is non-specifically attached to a dextran coated surface and not properly embedded in a cell membrane. However, it is apparent that the affinity of both fusion toxins for HER2 is weaker than the affinity of the individual domains for HER2. The $\mathrm{K}_{\mathrm{D}}$-values of $\mathrm{Z}_{\mathrm{HER} 2: 2891}$ and $\mathrm{ADAPT}_{6}$ for interaction with HER2 have previously been determined to $66 \mathrm{pM}$ and $0.5 \mathrm{nM}$, respectively [26,38]. A weaker affinity to HER2, when fused to truncated derivatives of ETA, has also been recorded previously for $Z_{\text {HER2:2891 }}$ and $\mathrm{ADAPT}_{6}$ [24,31]. An unexpected result of the Ligandtracer affinity measurement was that the interaction between $\mathrm{Z}_{\text {HER2:2891-ADAPT }}$-ABD-PE25 and HER2 was dominated by one single event and not two. However, the off-rate of $Z_{\mathrm{HER} 2: 2891}-\mathrm{ADAPT}_{6}-\mathrm{ABD}-\mathrm{PE} 25$ in the Biacore analysis was slower than the off-rate

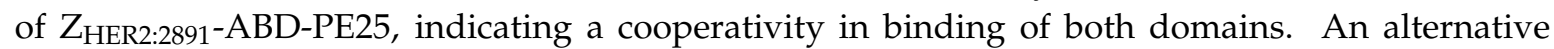
explanation is that flanking $\mathrm{ADAPT}_{6}$ with two domains $\left(\mathrm{Z}_{\mathrm{HER} 2: 2891}\right.$ and ABD-PE25) prevents its binding to HER2 on living cells due to steric hindrance. In this scenario however, $\mathrm{ADAPT}_{6}$ might act as an additional spacer between $\mathrm{Z}_{\mathrm{HER} 2: 2891}$ and PE25, permitting more efficient binding of the affibody molecule to HER2. 
The affinity of the fusion toxins to HSA and MSA was also determined in a Biacore instrument, and was similar to the interaction of other fusion proteins containing the same ABD-domain [31]. Consistent with observations on fusion toxins containing the same ABD, the affinity of both fusion toxins was stronger to HSA than to MSA [31].

A relatively long linker of 20 amino acids, dominated by serine, was used to connect all domains in both fusion toxins. The rationale behind this choice was that since both HER2 and HSA are relatively large compared to $\mathrm{Z}_{\mathrm{HER} 2: 2891}, \mathrm{ADAPT}_{6}$, and $\mathrm{ABD}$, long linkers could be necessary to allow simultaneous binding. Even though we did not compare different linkers in this study, is was clearly demonstrated by the flow cytometry experiments (Figure 2c,d), that the length was enough to allow simultaneous binding of HER2 and HSA. Investigation of different linkers could be an interesting follow-up study to the present one, and linker length could perhaps affect triggering of HER2 signaling or rate of internalization. Previous studies have shown that dimeric HER2 binding affibody molecules can affect signaling through e.g., the mitogen-activated protein kinase MAPK pathway, although the effect on e.g., cell proliferation was different for different cell lines $[39,40]$. Additionally, dimeric HER2 binding designed ankyrin repeat proteins, with different linker lengths, gave rise to different cytotoxic responses in HER2 overexpressing cell lines [41]. A difference between the two studies on dimeric affibody constructs and the study on dimeric designed ankyrin repeat proteins, was that a homo-dimer was used in the affibody studies but the designed ankyrin repeat proteins consisted of two domains binding to different parts of HER2, which is more similar to the dual-targeting domain, $\mathrm{Z}_{\mathrm{HER2}: 2891}-\mathrm{ADAPT}_{6}$, used in this study.

The toxicity ( $\mathrm{EC}_{50}$-value) of both fusion toxins to SKBR-3, SKOV3, and AU565 cells, all with high HER2 expression, was between 10 and $100 \mathrm{pM}$. This is similar to the $\mathrm{EC}_{50}$-values found previously for $\mathrm{ADAPT}_{6}$-ABD-PE25 on the same cell lines [31]. Since the affinity of ADAPT 6 -ABD-PE25 for HER2 is 10-fold weaker (15 nM) [31] compared to the affinity between $Z_{\text {HER2:2891-ABD-PE25 and HER2 }}$ $(1.9 \mathrm{nM})$, it appears that an affinity stronger than "low nanomolar" does not increase cytotoxicity of PE25-based fusion toxins towards these cell lines. However, it should be noted that the comparison between $\mathrm{ADAPT}_{6}$ and $\mathrm{Z}_{\mathrm{HER} 2: 2891}$ is an approximation, since they might affect internalization of HER2 differently. An additional result that points towards that $\mathrm{ADAPT}_{6}$ and $\mathrm{Z}_{\mathrm{HER} 2: 2891}$ confers a similar cytotoxicity in PE25-based constructs is that $Z_{\text {HER2:2891-ADAPT }}$-ABD-PE25 shows similar cytotoxicity towards the HER2 overexpressing cell lines. This fusion toxin has an even stronger affinity to HER2 on SKOV3 cells than ADAPT 6 -ABD-PE25 and $Z_{\text {HER2:2891-ABD-PE25. }}$

The in vivo biodistribution experiment suggested that the clearance route of the fusion toxins, when utilizing $Z_{\text {HER2:2891 }}$ as targeting domain, was mainly through the kidneys, in contrast to the use of $\mathrm{ADAPT}_{6}$ as targeting domain of PE25 which had a more pronounced clearance through the

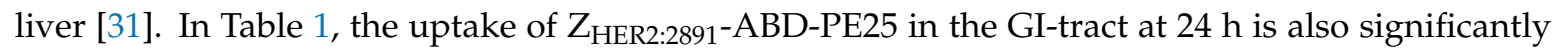
lower than the other two, as a consequence of the shift in clearance route to the kidneys. Clearance through the kidneys is more desirable than liver, since liver damage is a more common side effect of targeted cytotoxic drugs such as antibody drug conjugates [42]. It should be noted that neither $Z_{\text {HER2:2891 }}$ nor $\mathrm{ADAPT}_{6}$ is cross-reactive with murine HER2, so the uptake in different organs was not mediated by interaction with HER2. This means that the observed differences for the fusion toxins is not obscured by endogenous murine HER2 receptors in the mice, that could have contributed to a difference in the uptake of $Z_{\mathrm{HER} 2: 2891}$ or $\mathrm{ADAPT}_{6}$.

A possible continuation of the current study could be to investigate the efficacy of the fusion toxins in animal models with implanted HER2 expressing tumors. Of particular interest would be to determine if tumor growth can be slowed and survival of the animals can be prolonged, similar to what has previously been demonstrated for other affibody based fusion toxins [43,44]. Of particular interest would be to compare liver uptake and maximum tolerated dose for different variants, to get a general understanding of whether it is liver toxicity or something else that determines the maximum tolerated dose of Pseudomonas Exotoxin A-based fusion toxins. 
Cancer treatment regimens for patients with HER2 overexpression routinely includes HER2 specific antibodies or antibody-drug conjugates. Resistance to the drugs develops in some patients, but the tumors may still overexpress HER2 [45], which would allow treatment with potential drugs

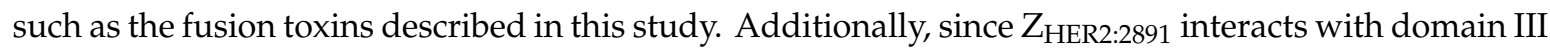
of HER2 [46], at a site which is distinct from the site of interaction with trastuzumab and pertuzumab, a combination therapy of the clinically validated antibodies or antibody drug conjugates and the

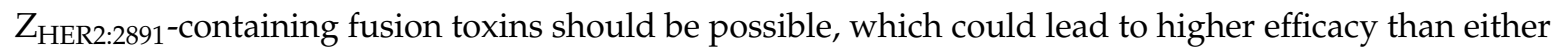
compound alone.

In conclusion, $\mathrm{Z}_{\mathrm{HER} 2: 2891}$ and $\mathrm{Z}_{\mathrm{HER} 2: 2891}-\mathrm{ADAPT}_{6}$ are efficient targeting domains for PE25-based fusion toxins, resulting in agents with high cytotoxicity and specificity for HER2 overexpressing cells. The cytotoxicity profiles and distribution in vivo suggest that $Z_{\mathrm{HER2} 2891}$ is superior compared to $\mathrm{Z}_{\mathrm{HER} 2: 2891}-\mathrm{ADAPT}_{6}$ and $\mathrm{ADAPT}_{6}$ as a targeting domain in the context of the present study.

Supplementary Materials: The following are available online at http://www.mdpi.com/1999-4923/12/4/391/s1; Figure S1: Analysis of molecular masses by mass spectrometry; Figure S2: Specificity of binding.

Author Contributions: Conceptualization, S.L., A.O., V.T., S.H. and T.G.; Methodology, M.A., A.O., V.T. and T.G.; Validation, H.D., M.A., A.O., V.T. and T.G.; Formal analysis, H.D., M.A., W.Y., J.G., T.X., A.O., V.T. and T.G.; Investigation, H.D., M.A., W.Y., S.L., H.L., J.G., T.X. and A.O.; Resources, A.O., V.T. and T.G.; Data curation, V.T. and T.G.; Writing—original draft preparation W.Y. and T.G.; Writing—review and editing, H.D., M.A., W.Y., S.L., H.L., J.G., T.X., A.O., V.T., S.H. and T.G.; Visualization, H.D., W.Y., T.X., V.T. and T.G.; supervision, V.T. and T.G.; project administration, T.G.; funding acquisition, A.O., V.T. and T.G. All authors have read and agreed to the published version of the manuscript.

Funding: The project was funded by the Swedish Agency for Innovation VINNOVA (2019/00104), the Swedish Cancer Society (Cancerfonden: CAN 2015/746, CAN 2017/425, CAN 2018/436 and CAN 2018/824). The salary of H.D. and W.Y. was supported by the Chinese Scholarship Council.

Acknowledgments: The authors are grateful to Andreas Hober for help with determination of the molecular masses of the fusion toxins by mass spectrometry.

Conflicts of Interest: The authors declare no conflict of interest.

\section{References}

1. Emde, A.; Köstler, W.J.; Yarden, Y. Therapeutic strategies and mechanisms of tumorigenesis of HER2-overexpressing breast cancer. Crit. Rev. Oncol. Hematol. 2012, 84, 49-57. [CrossRef]

2. Yan, M.; Schwaederle, M.; Arguello, D.; Millis, S.Z.; Gatalica, Z.; Kurzrock, R. HER2 expression status in diverse cancers: Review of results from 37,992 patients. Cancer Metastasis Rev. 2015, 34, 157-164. [CrossRef]

3. Citri, A.; Yarden, Y. EGF-ERBB signalling: Towards the systems level. Nat. Rev. Mol. Cell Biol. 2006, 7 , 505-516. [CrossRef] [PubMed]

4. Slamon, D.J.; Clark, G.M.; Wong, S.G.; Levin, W.J.; Ullrich, A.; McGuire, W.L. Human breast cancer: Correlation of relapse and survival with amplification of the HER-2/neu oncogene. Science 1987, 235, 177-182. [CrossRef]

5. Vogel, C.L.; Cobleigh, M.A.; Tripathy, D.; Gutheil, J.C.; Harris, L.N.; Fehrenbacher, L.; Slamon, D.J.; Murphy, M.; Novotny, W.F.; Burchmore, M.; et al. Efficacy and Safety of Trastuzumab as a Single Agent in First-Lin Treatment of HER2-Overexpressing Metastatic Breast Cancer. J. Clin. Oncol. 2003, 20, 719-726. [CrossRef] [PubMed]

6. von Minckwitz, G.; Procter, M.; de Azambuja, E.; Zardavas, D.; Benyunes, M.; Viale, G.; Suter, T.; Arahmani, A.; Rouchet, N.; Clark, E.; et al. Adjuvant Pertuzumab and Trastuzumab in Early HER2-Positive Breast Cancer. N. Engl. J. Med. 2017, 377, 122-131. [CrossRef] [PubMed]

7. Verma, S.; Miles, D.; Gianni, L.; Krop, I.E.; Welslau, M.; Baselga, J.; Pegram, M.; Oh, D.-Y.; Diéras, V.; Guardino, E.; et al. Trastuzumab emtansine for HER2-positive advanced breast cancer. N. Engl. J. Med. 2012, 367, 1783-1791. [CrossRef] [PubMed]

8. Keam, S.J. Trastuzumab Deruxtecan: First Approval. Drugs 2020, 80, 501-508. [CrossRef]

9. Mazor, R.; Onda, M.; Pastan, I. Immunogenicity of therapeutic recombinant immunotoxins. Immunol. Rev. 2016, 270, 152-164. [CrossRef] [PubMed] 
10. Kreitman, R.J.; Dearden, C.; Zinzani, P.L.; Delgado, J.; Karlin, L.; Robak, T.; Gladstone, D.E.; le Coutre, P.; Dietrich, S.; Gotic, M.; et al. Moxetumomab pasudotox in relapsed/refractory hairy cell leukemia. Leukemia 2018, 32, 1768-1777. [CrossRef]

11. Liu, W.; Onda, M.; Lee, B.; Kreitman, R.J.; Hassan, R.; Xiang, L.; Pastan, I. Recombinant immunotoxin engineered for low immunogenicity and antigenicity by identifying and silencing human B-cell epitopes. Proc. Natl. Acad. Sci. USA 2012, 109, 11782-11787. [CrossRef] [PubMed]

12. Onda, M.; Beers, R.; Xiang, L.; Nagata, S.; Wang, Q.-C.; Pastan, I. An immunotoxin with greatly reduced immunogenicity by identification and removal of B cell epitopes. Proc. Natl. Acad. Sci. USA 2008, 105, 11311-11316. [CrossRef] [PubMed]

13. Onda, M.; Beers, R.; Xiang, L.; Lee, B.; Weldon, J.E.; Kreitman, R.J.; Pastan, I. Recombinant immunotoxin against B-cell malignancies with no immunogenicity in mice by removal of B-cell epitopes. Proc. Natl. Acad. Sci. USA 2011, 108, 5742-5747. [CrossRef] [PubMed]

14. Mazor, R.; Vassall, A.N.; Eberle, J.A.; Beers, R.; Weldon, J.E.; Venzon, D.J.; Tsang, K.Y.; Benhar, I.; Pastan, I. Identification and elimination of an immunodominant T-cell epitope in recombinant immunotoxins based on Pseudomonas exotoxin A. Proc. Natl. Acad. Sci. USA 2012, 109, E3597-E3603. [CrossRef]

15. Weldon, J.E.; Skarzynski, M.; Therres, J.A.; Ostovitz, J.R.; Zhou, H.; Kreitman, R.J.; Pastan, I. Designing the Furin-Cleavable Linker in Recombinant Immunotoxins Based on Pseudomonas Exotoxin, A. Bioconjug. Chem. 2015, 26, 1120-1128. [CrossRef]

16. Mazor, R.; Onda, M.; Park, D.; Addissie, S.; Xiang, L. Dual B- and T-cell de-immunization of recombinant immunotoxin targeting mesothelin with high cytotoxic activity. Oncotarget 2016, 7, 29916-29926. [CrossRef]

17. Bera, T.K.; Onda, M.; Kreitman, R.J.; Pastan, I. An improved recombinant Fab-immunotoxin targeting CD22 expressing malignancies. Leuk. Res. 2014, 38, 1224-1229. [CrossRef]

18. Friedman, M.; Nordberg, E.; Höidén-Guthenberg, I.; Brismar, H.; Adams, G.P.; Nilsson, F.Y.; Carlsson, J.; Ståhl, S. Phage display selection of Affibody molecules with specific binding to the extracellular domain of the epidermal growth factor receptor. Protein Eng. Des. Sel. 2007, 20, 189-199. [CrossRef]

19. Orlova, A.; Magnusson, M.; Eriksson, T.L.J.; Nilsson, M.; Larsson, B.; Höiden-Guthenberg, I.; Widström, C.; Carlsson, J.; Tolmachev, V.; Ståhl, S.; et al. Tumor imaging using a picomolar affinity HER2 binding Affibody molecule. Cancer Res. 2006, 66, 4339-4348. [CrossRef]

20. Kronqvist, N.; Malm, M.; Göstring, L.; Gunneriusson, E.; Nilsson, M.; Höidén-Guthenberg, I.; Gedda, L.; Frejd, F.Y.; Sthl, S.; Löfblom, J. Combining phage and staphylococcal surface display for generation of ErbB3-specific Affibody molecules. Protein Eng. Des. Sel. 2011, 24, 385-396. [CrossRef]

21. Li, J.; Lundberg, E.; Vernet, E.; Larsson, B.; Höiden-Guthenberg, I.; Gräslund, T. Selection of affibody molecules to the ligand-binding site of the insulin-like growth factor-1 receptor. Biotechnol. Appl. Biochem. 2010, 55, 99-109. [CrossRef] [PubMed]

22. Honarvar, H.; Garousi, J.; Gunneriusson, E.; Höidén-Guthenberg, I.; Altai, M.; Widström, C.; Tolmachev, V.; Frejd, F.Y. Imaging of CAIX-expressing xenografts in vivo using ${ }^{99 \mathrm{~m}}$ Tc-HEHEHE-ZCAIX:1 Affibody molecule. Int. J. Oncol. 2015, 46, 513-520. [CrossRef]

23. Ståhl, S.; Gräslund, T.; Eriksson Karlström, A.; Frejd, F.Y.; Nygren, P.Å.; Löfblom, J. Affibody Molecules in Biotechnological and Medical Applications. Trends Biotechnol. 2017, 35, 691-712. [CrossRef] [PubMed]

24. Liu, H.; Seijsing, J.; Frejd, F.; Tolmachev, V.; Gräslund, T. Target-specific cytotoxic effects on HER2-expressing cells by the tripartite fusion toxin $\mathrm{Z}_{\mathrm{HER} 2: 2891}$-ABD-PE38X8, including a targeting affibody molecule and a half-life extension domain. Int. J. Oncol. 2015, 2, 601-609. [CrossRef] [PubMed]

25. Sörensen, J.; Velikyan, I.; Sandberg, D.; Wennborg, A.; Feldwisch, J.; Tolmachev, V.; Orlova, A.; Sandström, M.; Lubberink, M.; Olofsson, H.; et al. Measuring HER2-receptor expression in metastatic breast cancer using [68Ga]ABY-025 Affibody PET/CT. Theranostics 2016, 6, 262-271. [CrossRef] [PubMed]

26. Nilvebrant, J.; Åstrand, M.; Georgieva-Kotseva, M.; Björnmalm, M.; Löfblom, J.; Hober, S. Engineering of bispecific affinity proteins with high affinity for ERBB2 and adaptable binding to albumin. PLOS ONE 2014, 9, e103094. [CrossRef]

27. Nilvebrant, J.; Åstrand, M.; Löfblom, J.; Hober, S. Development and characterization of small bispecific albumin-binding domains with high affinity for ErbB3. Cell. Mol. Life Sci. 2013, 70, 3973-3985. [CrossRef]

28. Garousi, J.; Lindbo, S.; Nilvebrant, J.; Astrand, M.; Buijs, J.; Sandström, M.; Honarvar, H.; Orlova, A.; Tolmachev, V.; Hober, S. ADAPT, a novel scaffold protein-based probe for radionuclide imaging of molecular targets that are expressed in disseminated cancers. Cancer Res. 2015, 75, 4364-4371. [CrossRef] 
29. Garousi, J.; Lindbo, S.; Borin, J.; von Witting, E.; Vorobyeva, A.; Oroujeni, M.; Mitran, B.; Orlova, A.; Buijs, J.; Tolmachev, V.; et al. Comparative evaluation of dimeric and monomeric forms of ADAPT scaffold protein for targeting of HER2-expressing tumours. Eur. J. Pharm. Biopharm. 2019, 134, 37-48. [CrossRef]

30. Tolmachev, V.; Bragina, O.; von Witting, E.; Garousi, J.; Zelchan, R.; Sinilkin, I.; Medvedeva, A.; Doroshenko, A.; Vorobyeva, A.; Lindbo, S.; et al. First-in-humans Evaluation of [99mTc]-ADAPT 6 , a Novel Scaffold Protein for Visualization of HER2 Expression. Eur. J. Nucl. Med. Mol. Imaging 2019, 46, S166.

31. Liu, H.; Lindbo, S.; Ding, H.; Altai, M.; Garousi, J.; Orlova, A.; Tolmachev, V.; Hober, S.; Gräslund, T. Potent and specific fusion toxins consisting of a HER2-binding, ABD-derived affinity protein, fused to truncated versions of Pseudomonas exotoxin A. Int. J. Oncol. 2019, 55, 309-319. [CrossRef] [PubMed]

32. Tolmachev, V.; Orlova, A.; Pehrson, R.; Galli, J.; Baastrup, B.; Andersson, K.; Sandström, M.; Rosik, D.; Carlsson, J.; Lundqvist, H.; et al. Radionuclide therapy of HER2-positive microxenografts using a 177Lu-labeled HER2-specific Affibody molecule. Cancer Res. 2007, 67, 2773-2782. [CrossRef] [PubMed]

33. Roopenian, D.C.; Akilesh, S. FcRn: The neonatal Fc receptor comes of age. Nat. Rev. Immunol. 2007, 7, 715-725. [CrossRef] [PubMed]

34. Jonsson, A.; Dogan, J.; Herne, N.; Abrahmsén, L.; Nygren, P.Å. Engineering of a femtomolar affinity binding protein to human serum albumin. Protein Eng. Des. Sel. 2008, 21, 515-527. [CrossRef] [PubMed]

35. Altai, M.; Liu, H.; Ding, H.; Mitran, B.; Edqvist, P.-H.; Tolmachev, V.; Orlova, A.; Gräslund, T. Affibody-derived drug conjugates: Potent cytotoxic molecules for treatment of HER2 over-expressing tumors. J. Control. Release 2018, 288, 84-95. [CrossRef]

36. Björke, H.; Andersson, K. Measuring the affinity of a radioligand with its receptor using a rotating cell dish with in situ reference area. Appl. Radiat. Isot. 2006, 64, 32-37. [CrossRef]

37. Pastan, I.; Beers, R.; Bera, T.K. Recombinant Immunotoxins in the Treatment of Cancer. Methods Mol. Biol. 2004, 248, 503-518.

38. Feldwisch, J.; Tolmachev, V.; Lendel, C.; Herne, N.; Sjöberg, A.; Larsson, B.; Rosik, D.; Lindqvist, E.; Fant, G.; Höidén-Guthenberg, I.; et al. Design of an optimized scaffold for affibody molecules. J. Mol. Biol. 2010, 398, 232-247. [CrossRef]

39. Ekerljung, L.; Lindborg, M.; Gedda, L.; Frejd, F.Y.; Carlsson, J.; Lennartsson, J. Dimeric HER2-specific affibody molecules inhibit proliferation of the SKBR-3 breast cancer cell line. Biochem. Biophys. Res. Commun. 2008, 377, 489-494. [CrossRef]

40. Ekerljung, L.; Steffen, A.C.; Carlsson, J.; Lennartsson, J. Effects of HER2-binding affibody molecules on intracellular signaling pathways. Tumor Biol. 2006, 27, 201-210. [CrossRef]

41. Tamaskovic, R.; Schwill, M.; Nagy-Davidescu, G.; Jost, C.; Schaefer, D.C.; Verdurmen, W.P.R.; Schaefer, J.V.; Honegger, A.; Plückthun, A. Intermolecular biparatopic trapping of ErbB2 prevents compensatory activation of PI3K/AKT via RAS-p110 crosstalk. Nat. Commun. 2016, 7, 11672. [CrossRef] [PubMed]

42. Donaghy, H. Effects of antibody, drug and linker on the preclinical and clinical toxicities of antibody-drug conjugates. MAbs 2016, 8, 659-671. [CrossRef]

43. Zielinski, R.; Lyakhov, I.; Hassan, M.; Kuban, M.; Shafer-Weaver, K.; Gandjbakhche, A.; Capala, J. HER2-affitoxin: A potent therapeutic agent for the treatment of HER2-overexpressing tumors. Clin. Cancer Res. 2011, 17, 5071-5081. [CrossRef] [PubMed]

44. Guo, R.; Cao, L.; Guo, W.; Liu, H.; Xu, H.; Fang, Q.; Hong, Z. HER2-targeted immunotoxins with low nonspecific toxicity and immunogenicity. Biochem. Biophys. Res. Commun. 2016, 475, 93-99. [CrossRef] [PubMed]

45. Lewis Phillips, G.D.; Li, G.; Dugger, D.L.; Crocker, L.M.; Parsons, K.L.; Mai, E.; Blättler, W.A.; Lambert, J.M.; Chari, R.V.J.; Lutz, R.J.; et al. Targeting HER2-positive breast cancer with trastuzumab-DM1, an antibody-cytotoxic drug conjugate. Cancer Res. 2008, 68, 9280-9290. [CrossRef] [PubMed]

46. Eigenbrot, C.; Ultsch, M.; Dubnovitsky, A.; Abrahmsen, L.; Hard, T. Structural basis for high-affinity HER2 receptor binding by an engineered protein. Proc. Natl. Acad. Sci. USA 2010, 107, 15039-15044. [CrossRef]

(C) 2020 by the authors. Licensee MDPI, Basel, Switzerland. This article is an open access article distributed under the terms and conditions of the Creative Commons Attribution (CC BY) license (http://creativecommons.org/licenses/by/4.0/). 